\title{
PTPN11 hypomethylation is associated with gastric cancer progression
}

\author{
LELE XU $^{1 *}$, CONG ZHOU $^{2 *}$, RANRAN PAN ${ }^{2}$, JUNJIAN TANG $^{3}$, JINZHI WANG $^{4}$, \\ ${\text { BIN } \mathrm{LI}^{2} \text {, TIANYI HUANG }}^{2}$, SHIWEI DUAN ${ }^{2}$ and CHUNFANG XU ${ }^{1}$

\footnotetext{
${ }^{1}$ Department of Gastroenterology, The First Affiliated Hospital of Soochow University, Suzhou, Jiangsu 215200;

${ }^{2}$ Medical Genetics Center, School of Medicine, Ningbo University, Ningbo, Zhejiang 315211;

${ }^{3}$ Department of Vascular Surgery, Affiliated Hospital of Jiangnan University, Wuxi, Jiangsu 214000;

${ }^{4}$ Department of Cell Biology, School of Medicine, Soochow University, Suzhou, Jiangsu 215007, P.R. China
}

Received November 16, 2018; Accepted October 14, 2019

DOI: $10.3892 / \mathrm{ol} .2020 .11250$

\begin{abstract}
Protein tyrosine phosphatase non-receptor type 11 (PTPN11) encodes the tyrosine phosphatase SHP-2 that is overexpressed in gastric cancer (GC). In the present study, the association of PTPN11 methylation levels with the incidence of GC and its correlation with SHP-2 overexpression were investigated. The methylation levels of PTPN11 in tumor and adjacent normal tissues of 112 GC patients were assessed by quantitative methylation specific PCR (qMSP). The Cancer Genome Atlas (TCGA) public database was used to analyze the association between PTPN11 methylation and PTPN11 expression. Survival analyses were conducted in order to evaluate the prognostic value of PTPN11 methylation for GC. The results of the qMSP analysis indicated that the methylation levels of PTPN11 in GC tumor tissues were significantly decreased compared with those noted in the normal adjacent tissues (mean with standard deviation: $40.91 \pm 26.33$ vs. $51.99 \pm 37.37$, $\mathrm{P}=0.007)$. An inverse correlation between PTPN11 methylation levels and PTPN11 mRNA expression levels $\left(\mathrm{P}=4 \times 10^{-6}\right.$, $r=-0.237$ ) was noted. Subgroup analyses indicated that the association of PTPN11 hypomethylation with the incidence of GC was specific to male subjects $(\mathrm{P}=0.015)$, heavy drinking patients $(\mathrm{P}=0.019)$, patients with poor tumor differentiation $(\mathrm{P}=0.010)$ and patients with tumor node and metastasis
\end{abstract}

Correspondence to: Dr Chunfang Xu, Department of Gastroenterology, The First Affiliated Hospital of Soochow University, 889 Pinghai Road, Suzhou, Jiangsu 215200, P.R. China E-mail: xcf601@163.com

Dr Shiwei Duan, Medical Genetics Center, School of Medicine, Ningbo University, 818 Fenghua Road, Ningbo, Zhejiang 315211, P.R. China

E-mail: duanshiwei@nbu.edu.cn

*Contributed equally

Key words: protein tyrosine phosphatase non-receptor type 11, SHP-2, DNA methylation, gastric cancer, biomarker
(TNM) stage III+IV (P=0.008). Kaplan-Meier analyses and log-rank test suggested that PTPN11 hypomethylation was not associated with GC patient overall survival $(\mathrm{P}=0.605)$ and recurrence $(\mathrm{P}=0.485)$, although it could predict the recurrence of GC patients up to and including 60 years $(\leq 60, \mathrm{P}=0.049)$. The results indicated that $P T P N 11$ levels were hypomethylated in GC patients. TCGA data analysis suggested that PTPN11 hypomethylation could cause an upregulation in the transcription levels of PTPN11. Although, this may explain the pattern of SHP-2 overexpression in GC, additional studies are required to verify this hypothesis. The association of PTPN11 hypomethylation with GC incidence may be specific to male patients, heavy drinking patients, patients with poor tumor differentiation and patients with TNM stage of III+IV. PTPN11 hypomethylation can be considered a biomarker for the recurrence of GC patients with an age of 60 years or lower.

\section{Introduction}

In developing countries, stomach cancer is the third most frequently diagnosed cancer and is one of the leading causes of cancer-related death (1). The annual incidence and mortality of gastric cancer (GC) in China is estimated to $\sim 679,100$ and 498,000 cases, respectively (2). Despite recent advances in chemotherapy for $\mathrm{GC}$, the outcomes of anticancer therapy remain unsatisfactory.

Tyrosine-protein phosphatase non-receptor type 11 (PTPN11) encodes Src homology 2 domain-containing protein tyrosine phosphatase (SHP-2), which participates in multiple intracellular signaling pathways and plays an important role in tumor cell proliferation, apoptosis, invasion, metastasis and drug resistance $(3,4)$.

H. pylori $(\mathrm{Hp})$ infection is the primary risk factor for GC (5). Previously, evidence suggests that the well-known carcinogenic protein Cag-A of $\mathrm{Hp}$ is associated with SHP-2 expression in gastric mucosal epithelial cells. The Cag-A protein is released by Hp, enters epithelial cells via the type IV secretion system and is activated by tyrosine phosphorylation, which enables this protein to acquire the ability to interact with the tumor promoting enzyme tyrosine phosphorylase SHP-2. This process is regulated by host cell phosphatase and 
affects a large number of downstream pathways ultimately leading to decreased adhesion and polarity of epithelial cells $(3,6,7)$. Therefore, SHP-2 is considered one of the key proteins that links Cag-A with gastric cancer. However, only a limited number of patients with Hp-positive chronic gastritis or a peptic ulcer eventually develop into GC (8). This suggests that specific differences may appear between $\mathrm{Hp}$-infected hosts, such as genetic or epigenetic changes associated with the PTPN11 gene, or the differences noted in SHP-2 protein expression.

PTPN11 mutations have been extensively investigated in the past years. Germline mutations in PTPN11 cause Noonan syndrome (9-11) and its clinically related Leopard syndrome (12), whereas somatic mutations of PTPN11 contribute to leukemogenesis (13-17), as well as in the development of specific solid tumors, including neuroblastoma $(18,19)$, metachondromatosis $(20,21)$, brain tumors (22-24), neurofibromatosis (25), optic nerve pilomyxoid astrocytoma (26), breast carcinoma $(27,28)$, colorectal cancer $(29,30)$ and Ewing sarcoma (31). However, oncogenic mutations of PTPN11 are rare in the majority of solid tumors including $\operatorname{GC}(32,33)$.

Previous studies have detected the presence of PTPN11 polymorphisms in GC (34-36). However, these PTPN11 polymorphisms were shown to be associated with gastric atrophy instead of GC in Chinese and Japanese subjects $(37,38)$. These findings indicated that with the exception of mutations and polymorphisms, additional abnormal expression changes in the PTPN11 gene were involved in the development of GC.

Previously, the role of DNA methylation in the study of GC has received increasing attention in the identification of the mechanisms responsible for GC formation (39). However, the association between PTPN11 methylation and GC has not been reported to date. Therefore, the current study aimed to investigate the contribution of PTPN11 methylation in GC.

\section{Materials and methods}

Study subjects. A total of 112 GC patients (mean, 56.56; range, 21-83 years), including 76 male and 36 female patients, were recruited in the First Affiliated Hospital of Soochow University between December 2010 and April 2014. Gastric mucosa tissues of the primary tumor site and the corresponding adjacent normal tissues ( $5 \mathrm{~cm}$ away from the tumor) were collected from the patients. During this period, the GC patients were followed up and their survival data was collected. The patients were diagnosed by pathological examination and none of them received radiotherapy or chemotherapy prior to surgical resection. All patients who participated in the present study had signed an informed consent form. The study was approved by the Ethics Committee of Ningbo University.

DNA extraction, bisulphite conversion and sequencing. Total DNA was extracted from the tissue samples by the EZNA ${ }^{\mathrm{TM}}$ Tissue DNA kit (Omega Bio-Tek, Inc.) and its concentration was determined using a Nanodrop 2000 spectrophotometer (Thermo Fisher Scientific, Inc.). Bisulphite treatment was achieved using the EZ DNA Methylation-Gold kit ${ }^{\mathrm{TM}}$ (Zymo Research Corp.). Typically, $500 \mathrm{ng}$ of the original DNA sample was denatured by $\mathrm{NaOH}$ and bisulphite was used to convert the unmethylated cytosine to uracil, while the methylated cytosine remained unchanged (40). The total volume of the reaction was $30 \mu \mathrm{l}$. In addition, a part of the bisulphite-converted products were randomly selected for Sanger sequencing to verify the specificity of the quantitative methylation specific PCR (qMSP) assay.

SYBR green-based qMSP. The SYBR green-based qMSP used $\beta$-actin $(A C T B)$ as an internal control. The qMSP reaction consisted of $10 \mu \mathrm{l}$ SYBR Green I Master mix (Roche Diagnostics), $1 \mu \mathrm{l}$ primers and $1.0 \mu \mathrm{l}$ bisulphite-modified DNA template $(10 \mathrm{ng} / \mu \mathrm{l})$. The reaction volume was made up to $20 \mu \mathrm{l}$ by addition of $\mathrm{ddH}_{2} \mathrm{O}$. The primer sequences used in the qMSP assays were the following: 5'-GAGGTTCGG AGATAGTAGGTAAT-3' for the PTPN11 forward primer, 5'-GATTTCATTCATTTCGTTCCACAA-3' for the PTPN11 reverse primer, 5'-TGGTGATGGAGGAGGTTTAGTAAG T-3' for the $A C T B$ forward primer and 5'-AACCAATAAAAC CTACTCCTCCCTTAA-3' for the $A C T B$ reverse primer. The primers used in the present study were designed by the Primer Premier 5.0 software (PREMIER Biosoft Inc.). The designed primers were evaluated using Oligo 6.0 software (DBA Oligo Inc.) and NCBI primer-blast tool (https://www.ncbi.nlm.nih. gov/tools/primer-blast/). The PCR reactions were initiated at $95^{\circ} \mathrm{C}$ for $10 \mathrm{~min}$, followed by 45 cycles at $95^{\circ} \mathrm{C}$ for $30 \mathrm{sec}$ and $58^{\circ} \mathrm{C}$ and $72^{\circ} \mathrm{C}$ for $30 \mathrm{sec}$. A melting curve analysis was used at $95^{\circ} \mathrm{C}$ for $15 \mathrm{sec}$ and at $58^{\circ} \mathrm{C}$ for $1 \mathrm{~min}$. Subsequently, the temperature was increased every sec for $0.11^{\circ} \mathrm{C}$ until it reached $95^{\circ} \mathrm{C}$. The percentage of methylated reference (PMR) was calculated so as to represent the PTPN11 methylation levels. The equation used was as follows: $\left[\mathrm{PMR}=2^{-\Delta \Delta \mathrm{Cq}} \mathrm{X} 100 \%\right.$, $\Delta \Delta \mathrm{Cq}=$ sample DNA $\left(\mathrm{Cq}_{\mathrm{PTPN} 11}-\mathrm{Cq}_{\mathrm{ACTB}}\right)$-fully methylated DNA $\left.\left(\mathrm{Cq}_{\mathrm{PTPN} 11}-\mathrm{Cq}_{\mathrm{ACTB}}\right)\right](41)$.

Bioinformatic analysis. The methylation levels of PTPN11 and the expression profiles of this gene [Stomach Adenocarcinoma, The Cancer Genome Atlas (TCGA), Provisional] were available from cBioPortal (http://www. cbioportal.org/). The data comprised 478 GC samples from which DNA was extracted. The samples were used to evaluate the correlation between PTPN11 methylation and mRNA expression levels. A total of 177 samples were derived from subjects with Hp infection. The PTPN11 methylation levels were obtained from the TCGA gastric cancer database, including three tumor $\mathrm{Hp}(+), 17$ tumor $\mathrm{Hp}(-), 58$ non-tumor $\mathrm{Hp}(+)$ and 99 non-tumor $\mathrm{Hp}(-)$ samples.

Statistical analysis. SPSS 16.0 software (SPSS Inc.) was used for statistical analysis. The normal distributed data were described as mean \pm standard deviation, and the non-normal distributed data were described as median with interquartile ranges. The paired sample t test was used to assess the differences in the methylation levels between tumor and adjacent normal tissues. The data were analyzed following subgroup analysis. The spearman rank test was used to assess the association between PTPN11 methylation levels and PTPN11 expression levels. Kaplan-Meier and log-rank test analyses were applied to assess patient survival. A non-parametric Mann-Whitney U test and two independent sample t-tests were used to calculate differences in PTPN11 methylation in $\mathrm{Hp}$-infected samples and non-Hp-infected samples. A 


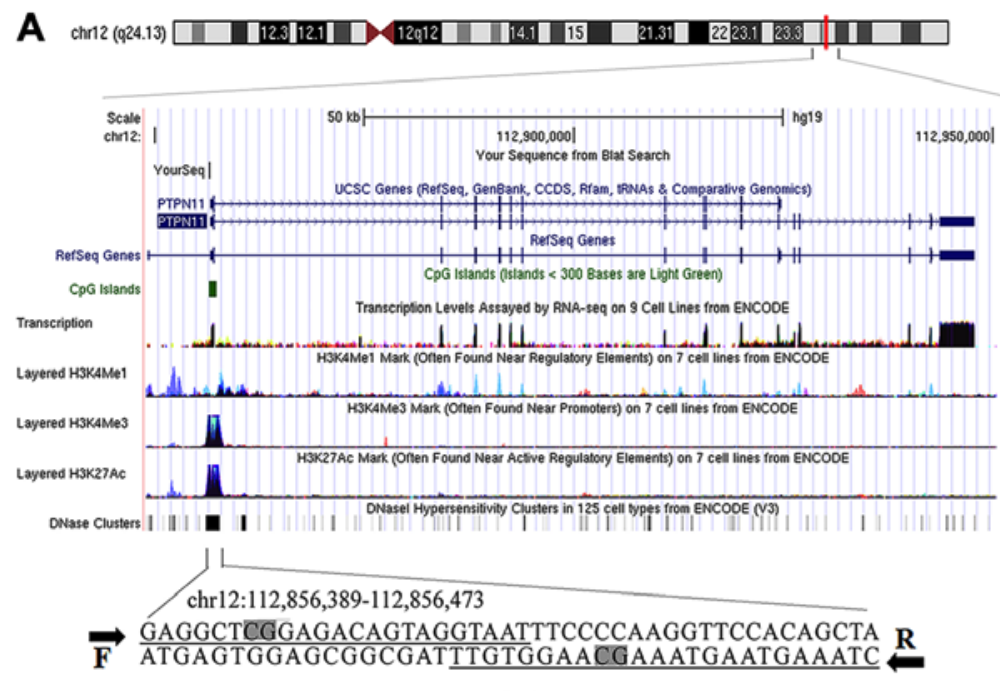

B $58^{\circ} \mathrm{C}$

C

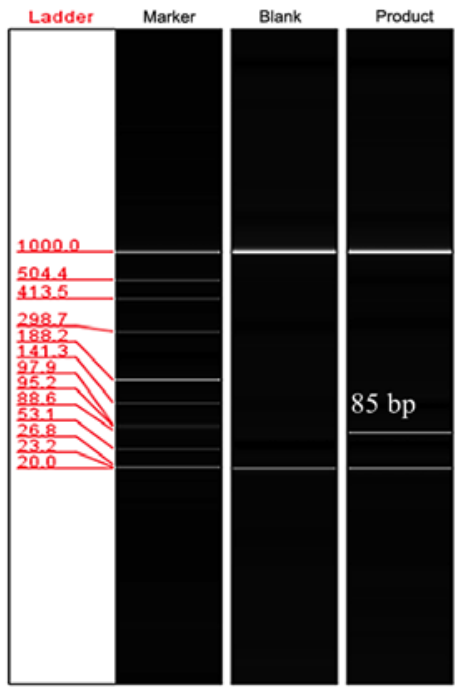

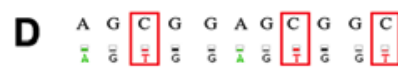
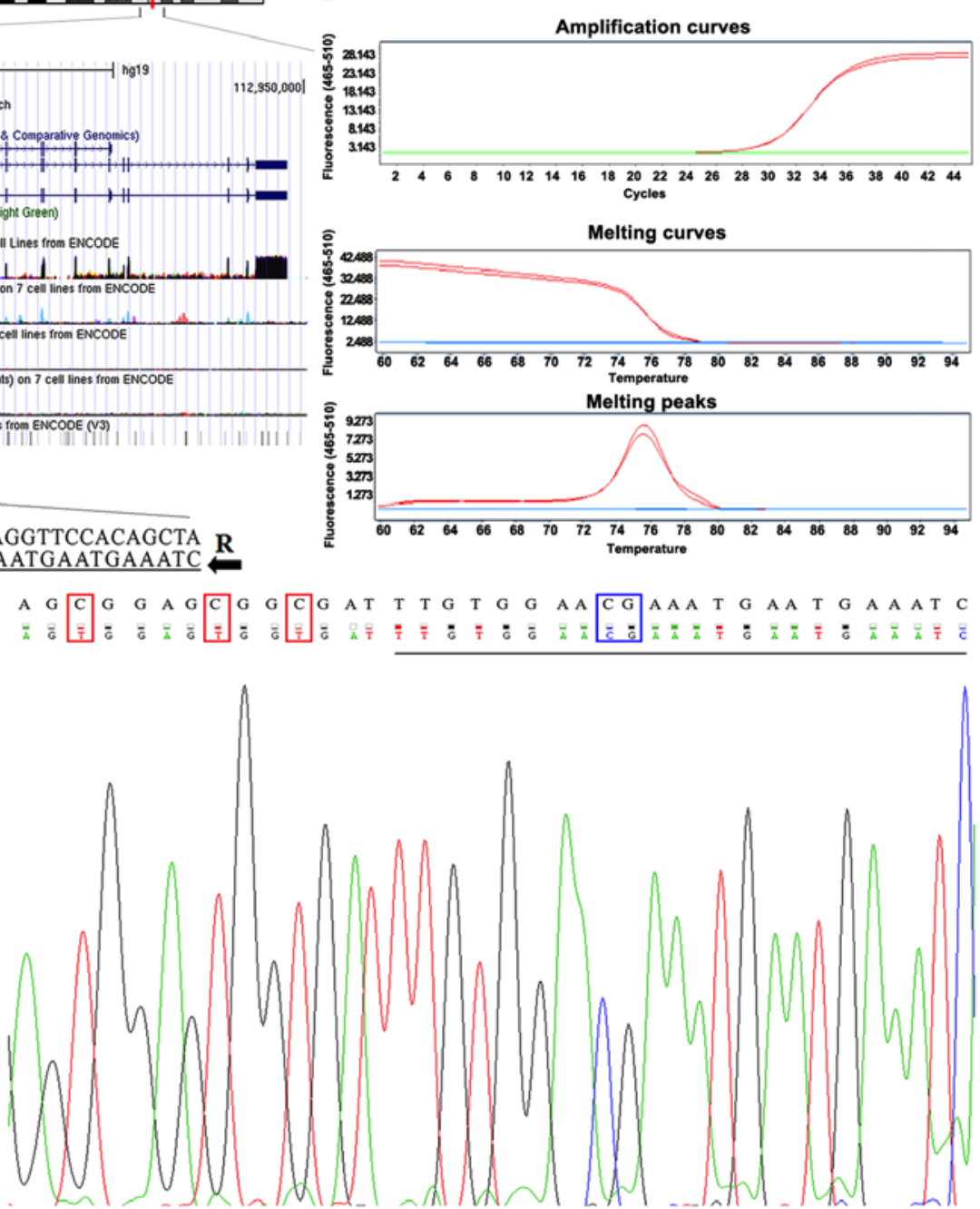

Figure 1. Molecular features and quality control samples of the PTPN11 qMSP assay. (A) F and R represent forward and reverse primers, respectively. CpG sites in primer sequences are highlighted in grey. (B) Amplification curves and melting curves of PTPN11 when qMSP was conducted at $58^{\circ} \mathrm{C}$. (C) The results of the capillary electrophoresis for the amplification fragment $(85 \mathrm{bp}$ ). (D) Sequencing of the bisulphite-converted product. The first line was the original sequence and the second line was the sequencing result. The primer binding position was underlined. The $\mathrm{CpG}$ cytosine site and the altered cytosines are shown in blue and red boxes, respectively. PTPN11 qMSP, Tyrosine-Protein Phosphatase Non-Receptor Type 11 quantitative methylation specific PCR.

two-sided $\mathrm{P}<0.05$ was considered to indicate a statistically significant difference.

\section{Results}

Verification of experimental reliability. The specificity of primers in this experiment was verified by Oligo 6.0 software and NCBI primer-blast tool. The evaluation indicated that the primers were methylation-specific. Each of the upstream and downstream primers used in the present study contained one $\mathrm{CpG}$ cytosine site and multiple non- $\mathrm{CpG}$ cytosine sites (Fig. 1A). The SYBR-green qMSP product formed a single dissolution curve at $\sim 76^{\circ} \mathrm{C}$, suggesting that the qMSP product exhibited a uniform melting temperature (Fig. 1B). In addition, the qMSP product was further analyzed by automated capillary electrophoresis and the results indicated a single band of $85 \mathrm{bp}$, confirming that the amplified qMSP products were homogenous (Fig. 1C). To further verify the specificity of the primers, random qMSP products were selected for Sanger sequencing and the results confirmed that the bisulfite conversion of the DNA template was complete (Fig. 1D). Therefore, all the aforementioned quality control results indicated that the qMSP process was unlikely to amplify fragments that were incompletely converted.

PTPN11 hypomethylation exists in GC and upregulates PTPN11 expression. The results indicated that the PTPN11 promoter was significantly hypomethylated in GC tissues compared with its corresponding methylation levels in the adjacent normal tissues [mean with standard deviation (SD): $40.91 \pm 26.33$ vs. $51.99 \pm 37.37, \mathrm{P}=0.007$, Fig. $2 \mathrm{~A}]$. In addition, PTPN11 expression data was extracted from 478 GC samples present in the TCGA database of Stomach Adenocarcinoma. The results indicated an inverse correlation between PTPN11 methylation and PTPN11 expression $\left(\mathrm{P}=4 \times 10^{-6}, r=-0.237\right.$, Fig. $\left.2 \mathrm{~B}\right)$.

Results of the subgroup analyses. Subgroup analyses by different clinical phenotypes were performed to compare 



Figure 2. PTPN11 hypomethylation in the current study and the inverse correlation between PTPN11 methylation and mRNA expression in the TCGA data mining study. (A) Comparisons of PTPN11 methylation between tumor and adjacent normal tissues revealed that PTPN11 was hypomethylated in gastric cancer ( $40.91 \pm 26.33$ vs. $51.99 \pm 37.37, \mathrm{P}=0.007)$, the plot described presents the mean with standard deviation. (B) The expression data comprising $478 \mathrm{GC}$ samples were extracted from the TCGA database of the Stomach Adenocarcinoma (TCGA, Provisional). An inverse correlation between PTPN11 methylation and mRNA expression levels was found $\left(\mathrm{P}=3.8 \times 10^{-6}, r=-0.237\right)$. PTPN11, tyrosine-protein phosphatase non-receptor type 11; TGCA, The Cancer Genome Atlas.


Differentiation

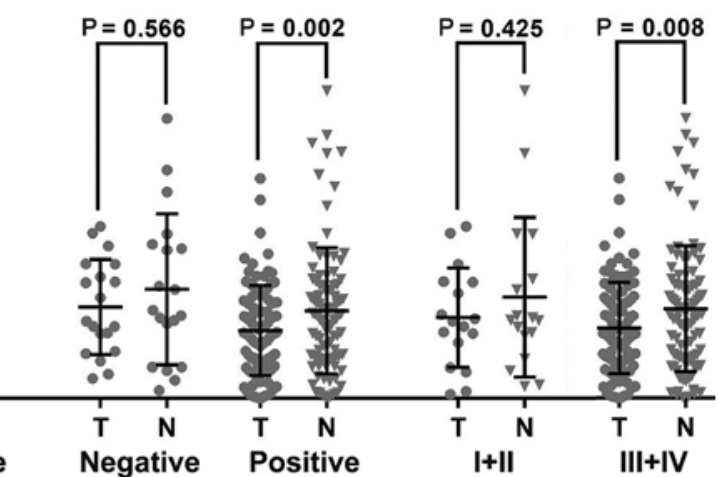

Lymphatic metastasis

TNM stage

Figure 3. Subgroup analysis by clinical characteristics. (A) Subgroup tests by gender and drinking history. (B) Subgroup tests by gastric cancer differentiation, LN and TNM stage. The plots are presented as mean with standard deviation. The P-value was calculated by the paired-samples $t$ test. A significant P-value was indicated in the following subgroups: Male subjects ( $39.44 \pm 25.93$ vs. $52.06 \pm 37.10, \mathrm{P}=0.015)$, heavy drinking subjects $(36.01 \pm 21.16$ vs. $60.07 \pm 46.66, \mathrm{P}=0$. 019), low/no differentiation ( $39.97 \pm 26.01$ vs. $50.96 \pm 35.90, \mathrm{P}=0.010)$, positive $\mathrm{LN}(39.45 \pm 26.20$ vs. $53.34 \pm 38.49, \mathrm{P}=0.002)$ and TNM stage III+IV (38.62 \pm 25.72 vs. $49.91 \pm 36.00, \mathrm{P}=0.008)$. TNM, tumor, node, metastasis; $\mathrm{LN}$, lymphatic metastasis; $\mathrm{T}$, tumor tissue; $\mathrm{N}$, adjacent normal tissue.

PTPN11 methylation levels between the tumor and adjacent normal samples. The data demonstrated that PTPN11 hypomethylation was specific to male subjects $(39.44 \pm 25.93$ vs. $52.06 \pm 37.10, \mathrm{P}=0.015)$ and the patients with history of heavy drinking (36.01 \pm 21.16 vs. $60.07 \pm 46.66, \mathrm{P}=0.019$, Fig. $3 \mathrm{~A})$. In addition, the association of PTPN11 hypomethylation with $\mathrm{GC}$ was specific to patients with low/no tumor differentiation (39.97 \pm 26.01 vs. $50.96 \pm 35.90, P=0.010$ ), positive lymphatic 

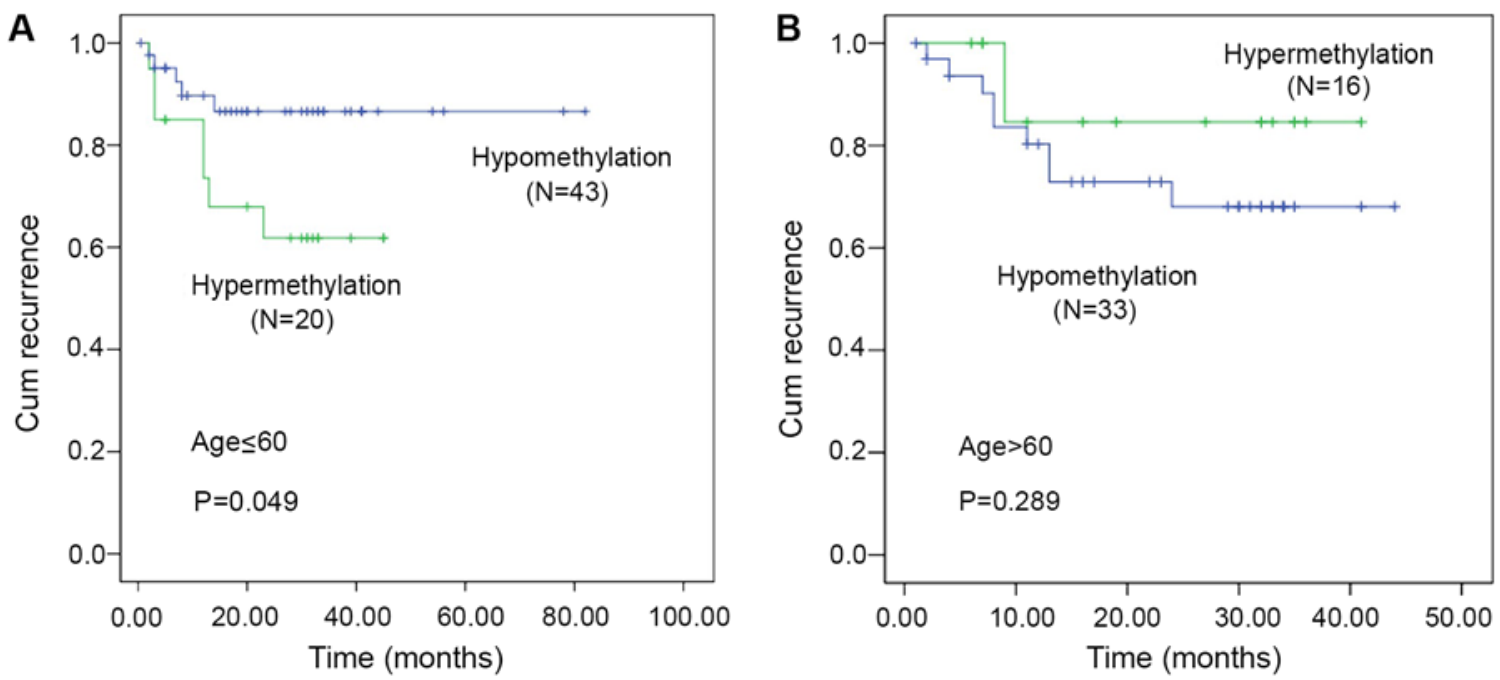

Figure 4. Prognostic value of PTPN11 methylation and tumor recurrence in gastric cancer patients of different age groups. Kaplan-Meier analysis was used to evaluate the prognostic value of PTPN11 hypomethylation. (A) In the age $\leq 60$ subgroup, the hypomethylation cohort exhibited a higher recurrence rate of gastric cancer (mean recurrence: 25.03 vs. 22.25 months, $\mathrm{P}=0.049$ ). (B) In the age $>60$ subgroup, no significant differences were shown between the hypermethylation and hypomethylation cohorts (mean recurrence: 22.19 vs. 22.76 months, $\mathrm{P}=0.289$ ). The groups with higher methylation levels in the tumor tissues compared with those noted in the adjacent normal tissues were defined as the hypermethylation cohort, whereas these with lower methylation levels in tumor vs. normal tissues were defined as the hypomethylation cohort. PTPN11, tyrosine-protein phosphatase non-receptor type 11.

metastasis $[\mathrm{LN}(+), 39.45 \pm 26.20$ vs. $53.34 \pm 38.49, \mathrm{P}=0.002]$ and tumor, node and metastasis (TNM) stage III+IV (38.62 \pm 25.72 vs. $49.91 \pm 36.00, \mathrm{P}=0.008$; Fig. 3B).

Hypomethylation cohort aged $\leq 60$ tends to have a higher recurrence rate. During a seven-year follow-up of 112 GC patients, five patients were lost to follow-up and 34 patients did not survive. The groups that exhibited higher tumor methylation levels compared with those noted in the adjacent normal tumors were defined as the hypermethylation cohort. The subjects that exhibited lower methylation levels in tumor vs. normal tissues were defined as the hypomethylation cohort. Kaplan-Meier analysis indicated no statistical significance between PTPN11 methylation levels and overall survival $(\mathrm{P}=0.484)$ or tumor recurrence $(\mathrm{P}=0.485)$. However, when stratified by age, the hypomethylation cohort aged $\leq 60$ years demonstrated a higher recurrence rate of GC (mean recurrence: 25.03 vs. 22.25 months, $\mathrm{P}=0.049$; Fig. $4 \mathrm{~A}$ ). In addition, no significant association was noted between PTPN11 methylation levels and GC recurrence in different methylation cohorts aged $>60$ years (mean recurrence: 22.19 months vs. 22.76 months, $\mathrm{P}=0.289$, Fig. 4B).

Association between Hp infection and PTPN11 hypomethylation. To further investigate the association between $\mathrm{Hp}$ infection and PTPN11 hypomethylation, the data from the samples and those from the TCGA database were analyzed (eight CpGs, Fig. 5A). In China, the detection of $\mathrm{Hp}$ is not a routine assay used in the screening of gastric cancer. In the present study, the samples were isolated from 9 patients with $\mathrm{Hp}$, including one $\mathrm{Hp}(+)$ patient and eight $\mathrm{Hp}(-)$ patients. The data indicated that the tumor $\mathrm{Hp}(+)$ tissues exhibited decreased PTPN11 methylation levels compared with those noted in the non-tumor $\mathrm{Hp}(+)$ tissues (PMR: 46.88 vs. 53.62). Similarly, the tumor $\mathrm{Hp}(-)$ tissues exhibited lower PTPN11 methylation levels than the non-tumor $\mathrm{Hp}(-)$ tissues although the difference was not significant (PMR: $43.59 \pm 27.90$ vs. $50.76 \pm 31.21$, $\mathrm{P}=0.664$, Fig. 5B). In addition, the methylation levels of eight $\mathrm{CpG}$ sites from the TCGA database with Hp infection were compared (Fig. 5A). The analysis demonstrated that the Hp infection status in the tumor samples was not associated with the levels of PTPN11 methylation. However, Hp infection was associated with hypermethylation of 2 PTPN11 CG sites in non-tumor tissues (cg09337511: $\mathrm{P}=0.027, \operatorname{cg} 24032304: \mathrm{P}=0.016)$. A total of four PTPN11 CG sites were noted that exhibited significant hypomethylation in the tumor $\mathrm{Hp}(-)$ compared with the corresponding non-tumor $\mathrm{Hp}(-)$ tissues, $(\operatorname{cg} 10069827$ : $\mathrm{P}=0.003$, cg08573574: $\mathrm{P}=0.011, \operatorname{cg} 09337511: \mathrm{P}=0.023, \operatorname{cg} 27541540$ : $\mathrm{P}=0.0003)$.

\section{Discussion}

Deregulation of SHP-2 (a protein encoded by PTPN11) by the Hp-related protein Cag-A can lead to GC risk (3). Although $\sim 70 \%$ of patients with GC are Hp-positive, only $1-2 \%$ of patients with chronic gastritis or Hp-positive peptic ulcer eventually develop GC (42). The expression levels of the SHP-2 protein were increased in $\mathrm{Hp}(+) \mathrm{GC}$ patients, although the differences noted were not significant (43). In the current study, it was demonstrated that PTPN11 was hypomethylated in GC, which has not been previously reported. Since abnormal gene methylation always interferes with expression (44), it was hypothesized that hypomethylation of PTPN11 may be one of the mechanisms involved in the development of GC.

PTPNI1 is a specific gene, which exhibits a two-sided effect in cancer progression (45). PTPN11 has been characterized as a tumor suppressor gene $(46,47)$ in liver cancer and as a proto-oncogene in leukemia (45). PTPN11 expression was increased in leukemia (48), breast cancer (49) and in thyroid tumors (50), whereas it was decreased in colon (51) and liver cancer $(46,52)$. Previous studies have shown an increase in PTPN11 mRNA and protein levels in GC $(43,53,54)$, suggesting 

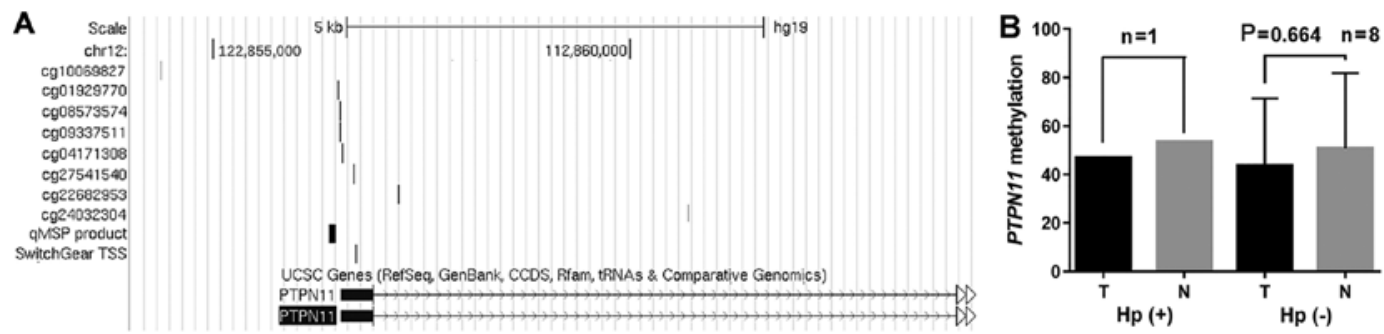

C PTPN11 methylation ( $\beta$ value)

\begin{tabular}{|c|c|c|c|c|c|c|c|}
\hline \multirow{3}{*}{ Target ID } & \multirow{3}{*}{$\begin{array}{l}\text { Genetic } \\
\text { position }\end{array}$} & \multicolumn{6}{|c|}{ PTPN11 methylation ( $\beta$ value) } \\
\hline & & \multicolumn{2}{|c|}{$\mathrm{T}$} & \multirow{2}{*}{$P_{1}$} & \multicolumn{2}{|c|}{$\mathrm{N}$} & \multirow{2}{*}{$P_{2}$} \\
\hline & & $\mathrm{Hp}(+)(n=3)$ & $H p(-)(n=58)$ & & $\mathrm{Hp}(+)(n=3)$ & $\mathrm{Hp}(-)(n=99)$ & \\
\hline cg10069827 & TSS -2347 & $0.95 \pm 0.01$ & $0.95(0.93,0.96)$ & 0.653 & $0.94 \pm 0.03$ & $0.95(0.95,0.96)$ & 0.178 \\
\hline cg01929770 & TSS -221 & $0.03 \pm 0.01$ & $0.03(0.02,0.03)$ & 1.000 & $0.03 \pm 0.00$ & $0.03(0.02,0.03)$ & 0.842 \\
\hline cg 08573574 & TSS - 197 & $0.02 \pm 0.00$ & $0.02 \pm 0.00$ & 0.477 & $0.02 \pm 0.00$ & $0.02 \pm 0.00$ & 0.609 \\
\hline cg09337511 & TSS -196 & $0.02 \pm 0.00$ & $0.02(0.02,0.02)$ & 0.584 & $0.02 \pm 0.01$ & $0.02 \pm 0.00$ & $0.027^{*}$ \\
\hline cg 04171308 & TSS -174 & $0.06 \pm 0.01$ & $0.06 \pm 0.01$ & 0.896 & $0.06 \pm 0.01$ & $0.06 \pm 0.01$ & 0.500 \\
\hline cg 27541540 & TSS - 23 & $0.05 \pm 0.02$ & $0.03(0.02,0.03)$ & 0.153 & $0.03 \pm 0.02$ & $0.03(0.03,0.05)$ & 0.093 \\
\hline cg22682953 & TSS 510 & $0.04 \pm 0.00$ & $0.03 \pm 0.01$ & 0.756 & $0.04 \pm 0.01$ & $0.03 \pm 0.01$ & 0.509 \\
\hline $\operatorname{cg} 24032304$ & TSS 3975 & $0.42 \pm 0.07$ & $0.43 \pm 0.11$ & 0.941 & $0.49 \pm 0.13$ & $0.42 \pm 0.13$ & $0.016^{*}$ \\
\hline \multirow{2}{*}{ Target ID } & \multirow{2}{*}{$\begin{array}{l}\text { Genetic } \\
\text { position }\end{array}$} & \multicolumn{2}{|c|}{$\mathrm{Hp} \mathrm{(+)}$} & \multirow{2}{*}{$P_{3}$} & \multicolumn{2}{|c|}{ Hр (-) } & \multirow{2}{*}{$P_{4}$} \\
\hline & & $T(n=3)$ & $N(n=17)$ & & $T(n=58)$ & $N(n=99)$ & \\
\hline $\begin{array}{l}\text { cg10069827 } \\
\text { cg01929770 }\end{array}$ & $\begin{array}{l}\text { TSS -2347 } \\
\text { TSS -221 }\end{array}$ & $\begin{array}{l}0.95 \pm 0.01 \\
0.03 \pm 0.01\end{array}$ & $\begin{array}{l}0.94 \pm 0.03 \\
0.03 \pm 0.00\end{array}$ & $\begin{array}{l}0.656 \\
0.895\end{array}$ & $\begin{array}{l}0.95(0.93,0.96) \\
0.03(0.02,0.03)\end{array}$ & $\begin{array}{l}0.95(0.95,0.96) \\
0.03(0.02,0.03)\end{array}$ & $\begin{array}{l}0.003^{*} \\
0.822\end{array}$ \\
\hline cg08573574 & TSS -197 & $0.02 \pm 0.00$ & $0.02 \pm 0.00$ & 0.648 & $0.02 \pm 0.00$ & $0.02 \pm 0.00$ & $0.011^{*}$ \\
\hline cg09337511 & TSS - 196 & $0.02 \pm 0.00$ & $0.02 \pm 0.01$ & 0.411 & $0.02(0.02,0.02)$ & $0.02 \pm 0.00$ & $0.023^{*}$ \\
\hline cg04171308 & TSS -174 & $0.06 \pm 0.01$ & $0.06 \pm 0.01$ & 0.610 & $0.06 \pm 0.01$ & $0.06 \pm 0.01$ & 0.158 \\
\hline $\operatorname{cg} 27541540$ & TSS -23 & $0.05 \pm 0.02$ & $0.03 \pm 0.02$ & 0.337 & $0.03(0.02,0.03)$ & $0.03(0.03,0.05)$ & $3.0 \times 10^{-4}=$ \\
\hline $\operatorname{cg} 22682953$ & TSS 510 & $0.04 \pm 0.00$ & $0.04 \pm 0.01$ & 0.786 & $0.03 \pm 0.01$ & $0.03 \pm 0.01$ & 0.799 \\
\hline cg 24032304 & TSS 3975 & $0.42 \pm 0.07$ & $0.49 \pm 0.13$ & 0.379 & $0.43 \pm 0.11$ & $0.42 \pm 0.13$ & 0.467 \\
\hline
\end{tabular}

Figure 5. Association between Hp infection and PTPN11 methylation. (A) Genomic locations of the qMSP product, CpG sites in TCGA and SwitchGear TSS at PTPN11 locus (Hg19). (B) The samples were compared according to the Hp status and PTPN11 methylation levels of the tumor and the adjacent non-tumor tissues. The comparisons were performed using the paired sample $t$ test. (C) TCGA samples were grouped according to tumor status and Hp infection, and the association between PTPN11 methylation and Hp infection was analyzed. The normal distributed data were described as mean \pm standard deviation, and the non-normal distributed data were described as median with interquartile ranges. When the two sets of data were normally distributed, the P-value was calculated by the two independent sample $\mathrm{t}$ tests. In any other case, a non-parametric Mann-Whitney U test was used. "P<0.05. Hp, Helicobacter pylori; TGCA, The Cancer Genome Atlas; PTPN11, Tyrosine-Protein Phosphatase Non-Receptor Type 11; TSS, transcriptional start site; T, tumor tissue; N, non-tumor tissue; n, number; qMSP, quantitative methylation specific PCR.

that PTPN11 may be a proto-oncogene in GC. In the present study, the results indicated that PTPN11 was hypomethylated in GC. In addition, TCGA data analysis revealed an inverse correlation between PTPN11 methylation and PTPN11 expression. These findings may explain the decreased methylation pattern and the high expression profile of PTPN11 in GC.

In addition, subgroup analysis indicated that PTPNII hypomethylation was specific for male subjects and GC patients with a history of heavy drinking. Chinese men were more likely to suffer from GC and the male mortality rate in China was $\sim$ twice that noted in Chinese women (2). Heavy drinking is a risk factor for GC (55). Therefore, whether PTPN11 hypomethylation occurs only in male subjects and heavy drinkers requires further studies. In addition, it was found that PTPN11 hypomethylation was specific for poorly differentiated GC patients and TNM III+IV GC patients. Patients with advanced TNM staging exhibited a poor prognosis (56). Poorly differentiated cancer cells are also a feature of advanced GC. Therefore, the present study hypothesized that PTPN11 hypomethylation may be associated with the progression of GC, which can be further studied in the future.

Previous studies have shown that PTPN11 overexpression indicates poor prognosis in liver cancer patients (57). The PTPN11 rs2301756 polymorphism has been shown to be associated with decreased risk of GC and with an improved response to chemotherapy (34). In addition, the gene panel containing PTPN11 in colorectal cancer and oral squamous cell carcinoma has a high prognostic value $(58,59)$. The 3 -year survival rate of GC patients with high SHP-2 expression was significantly decreased compared with patients with low SHP-2 expression and the postoperative recurrence mortality of high SHP-2 expression was also significantly increased compared with patients with low SHP-2 expression (53). The correlation between the methylation status of the PTPN11 gene and the prognosis of GC has not been reported previously. Therefore, a 7-year follow-up of GC patients was performed in the current study and the parameters survival time and postoperative recurrence time were assessed. Although the current analysis indicated that PTPN11 methylation exhibited no prognostic value on the survival and recurrence of patients with GC, following stratification by age, it was shown that the hypomethylation cohort with an average age $\leq 60$ years exhibited a higher recurrence rate of GC. SHP-2 abnormalities were associated with tumor cell proliferation, invasion and metastasis (3). Young cancer patients may be more prone to tumor progression due to increased body metabolism compared with elderly cancer patients. Therefore, PTPN11 hypomethylation may be a prognostic indicator for postoperative recurrence of GC patients under 60 years of age.

Several studies have indicated that the SHP-2 protein, which is encoded by PTPN11 is an intracellular target of Cag-A $(3,6,8)$. This protein is a virulence factor of $\mathrm{Hp}(3,6,8)$. Recently, Jiang et al (43) demonstrated that although the expression levels of SHP-2 in the gastric cancer $\mathrm{Hp}(+)$ group were increased compared with those noted in the gastric cancer $\mathrm{Hp}(-)$ group, the differences noted were not statistically 
significant. The present study revealed that both Hp infection and tumor status may change the methylation levels of specific PTPN11 CpG sites. However, only one and three tumor $\mathrm{Hp}(+)$ samples were found in the samples used in the present study and in those derived from the TCGA database. Therefore, the present findings require verification in the future with larger sample sizes of subjects with Hp infection.

The present study exhibits certain limitations. Firstly, the samples used and those derived from the TCGA database were not sufficient to ensure a plausible association of GC incidence and PTPN11 methylation with the status of $\mathrm{Hp}$ (positive or negative). Therefore, the correlation between $\mathrm{Hp}$ infection and PTPN11 methylation should be further tested in larger datasets with known Hp infection status. Secondly, although an inverse association between PTPN11 methylation and mRNA expression was noted by TCGA data analysis, future work is required to evaluate whether PTPN11 hypomethylation can lead to elevated SHP-2 expression in GC patients.

In summary, the present study indicated that PTPN11 was hypomethylated in GC and that this could be associated with SHP-2 overexpression in GC. Future study is required to verify this hypothesis. Hypomethylation of PTPN11 may be specific for men, patients with a history of heavy drinking, patients with poor tumor differentiation and patients with TNM III+IV stage GC. In addition, the present study further demonstrated that PTPN11 hypomethylation could predict recurrence of GC in patients aged $\leq 60$ years.

\section{Acknowledgements}

Not applicable.

\section{Funding}

The present study was supported by the K. C. Wong Magna Fund in Ningbo University.

\section{Availability of data and materials}

The datasets used and/or analyzed during the present study are available from the corresponding author on reasonable request.

\section{Authors' contributions}

SD, CX and LX cenceived and designed the study and gave the final approval of the submitted version. CZ, RP, JT, JW, $\mathrm{BL}$ and $\mathrm{TH}$ performed the data analyses and conducted the experiments. $\mathrm{CZ}$ contributed to figure preparation. LX collected samples and wrote the paper. All the authors have read and approved the final manuscript.

\section{Ethics approval and consent to participate}

All patients who participated in the present study had signed an informed consent form. The study was approved by the Ethics Committee of Ningbo University.

\section{Patient consent for publication}

Written informed consent was obtained from each patient.

\section{Competing interests}

The authors declare that they have no competing interests.

\section{References}

1. Torre LA, Bray F, Siegel RL, Ferlay J, Lortet-Tieulent J and Jemal A: Global cancer statistics, 2012. CA Cancer J Clin 65: 87-108, 2015.

2. Chen W, Zheng R, Baade PD, Zhang S, Zeng H, Bray F, Jemal A, Yu XQ and He J: Cancer statistics in China, 2015. CA Cancer J Clin 66: 115-132, 2016.

3. Yamazaki S, Yamakawa A, Ito Y, Ohtani M, Higashi H, Hatakeyama M and Azuma T: The CagA protein of Helicobacter pylori is translocated into epithelial cells and binds to SHP-2 in human gastric mucosa. J Infect Dis 187: 334-337, 2003.

4. Zhang J, Zhang F and Niu R: Functions of Shp2 in cancer. J Cell Mol Med 19: 2075-2083, 2015.

5. Inoue K: Gastric cancer risk classification (ABC classification), Nihon Rinsho 71: 1472-1478, 2013 (In Japanese).

6. Hatakeyama M: H. pylori oncoprotein CagA and gastric cancer. Nihon Rinsho 70: 1699-1704, 2012 (In Japanese).

7. Hatakeyama M: Deregulation of SHP-2 tyrosine phosphatase by the Helicobacter pylori virulence factor CagA. Keio J Med 51 (Suppl 2): S26-S32, 2002.

8. Uemura N, Okamoto $\mathrm{S}$, Yamamoto $\mathrm{S}$, Matsumura $\mathrm{N}$, Yamaguchi S, Yamakido M, Taniyama K, Sasaki N and Schlemper RJ: Helicobacter pylori infection and the development of gastric cancer. N Engl J Med 345: 784-789, 2001.

9. Müller PJ, Rigbolt KT, Paterok D, Piehler J, Vanselow J, Lasonder E, Andersen JS, Schaper F and Sobota RM: Protein tyrosine phosphatase SHP2/PTPN11 mistargeting as a consequence of SH2-domain point mutations associated with Noonan Syndrome and leukemia. J Proteomics 84: 132-147, 2013.

10. Mutesa L, Pierquin G, Janin N, Segers K, Thomée C, Provenzi M and Bours V: Germline PTPN11 missense mutation in a case of Noonan syndrome associated with mediastinal and retroperitoneal neuroblastic tumors. Cancer Genet Cytogenet 182: 40-42, 2008.

11. Lee KA, Williams B, Roza K, Ferguson H, David K, Eddleman K, Stone J, Edelmann L, Richard G, Gelb BD and Kornreich R: PTPN11 analysis for the prenatal diagnosis of Noonan syndrome in fetuses with abnormal ultrasound findings. Clin Genet 75: 190-194, 2009.

12. Motegi S, Yokoyama Y, Ogino S, Yamada K, Uchiyama A, Perera B, Takeuchi Y, Ohnishi H and Ishikawa O: Pathogenesis of multiple lentigines in LEOPARD syndrome with PTPN11 gene mutation. Acta Derm Venereol 95: 978-984, 2015.

13. Tartaglia M, Niemeyer CM, Shannon KM and Loh ML: SHP-2 and myeloid malignancies. Curr Opin Hematol 11: 44-50, 2004.

14. Ibáñez M, Carbonell-Caballero J, García-Alonso L, Such E, Jiménez-Almazán J, Vidal E, Barragán E,López-Pavía M,LLop M, Martín I, et al: The mutational landscape of acute promyelocytic leukemia reveals an interacting network of co-occurrences and recurrent mutations. PLoS One 11: e0148346, 2016.

15. Chen L, Chen W, Mysliwski M, Serio J, Ropa J, Abulwerdi FA, Chan RJ, Patel JP, Tallman MS, Paietta E, et al: Mutated Ptpn11 alters leukemic stem cell frequency and reduces the sensitivity of acute myeloid leukemia cells to Mcl1 inhibition. Leukemia 29: 1290-1300, 2015.

16. Yuan L, Lu L, Yang Y, Sun H, Chen X, Huang Y, Wang X, Zou L and Bao L: Genetic mutational profiling analysis of T cell acute lymphoblastic leukemia reveal mutant FBXW7 as a prognostic indicator for inferior survival. Ann Hematol 94: 1817-1828, 2015.

17. Yang WY, Chen XJ, Wang SC, Guo Y, Liu TF, Chang LX, Liu F and Zhu XF: Gene mutations and clinical characteristics in children with juvenile myelomonocytic leukemia. Zhongguo Dang Dai Er Ke Za Zhi 17: 1-5, 2015 (In Chinese).

18. Pugh TJ, Morozova O, Attiyeh EF, Asgharzadeh S, Wei JS, Auclair D, Carter SL, Cibulskis K, Hanna M, Kiezun A, et al: The genetic landscape of high-risk neuroblastoma. Nat Genet 45: 279-284, 2013.

19. Obasaju P, Brondon J, Mir S, Fordham LA, Lee S and Blatt J: Somatic PTPN11 mutation in a child with neuroblastoma and protein losing enteropathy. J Pediatr Hematol Oncol 40: 328-330, 2018.

20. McFarlane J, Knight T, Sinha A, Cole T, Kiely N and Freeman R: Exostoses, enchondromatosis and metachondromatosis; diagnosis and management. Acta Orthop Belg 82: 102-105, 2016. 
21. Bowen ME, Boyden ED, Holm IA, Campos-Xavier B, Bonafé L, Superti-Furga A, Ikegawa S, Cormier-Daire V, Bovée JV, Pansuriya TC, et al: Loss-of-function mutations in PTPN11 cause metachondromatosis, but not Ollier disease or Maffucci syndrome. PLoS Genet 7: e1002050, 2011.

22. Siegfried A, Cances C, Denuelle M, Loukh N, Tauber M, Cavé H and Delisle MB: Noonan syndrome, PTPN11 mutations, and brain tumors. A clinical report and review of the literature. Am J Med Genet A 173: 1061-1065, 2017.

23. Rankin J, Short J, Turnpenny P, Castle B and Hanemann CO: Medulloblastoma in a patient with the PTPN11 p.Thr468Met mutation. Am J Med Genet A 161A: 2027-2029, 2013.

24. Roccograndi L, Binder ZA, Zhang L, Aceto N, Zhang Z, Bentires-Alj M, Nakano I, Dahmane N and O'Rourke DM: SHP2 regulates proliferation and tumorigenicity of glioma stem cells. J Neurooncol 135: 487-496, 2017.

25. Thiel C, Wilken M, Zenker M, Sticht H, Fahsold R, Gusek-Schneider GC and Rauch A: Independent NF1 and PTPN11 mutations in a family with neurofibromatosis-Noonan syndrome. Am J Med Genet A 149A: 1263-1267, 2009.

26. Nair S, Fort JA, Yachnis AT and Williams CA: Optic nerve pilomyxoid astrocytoma in a patient with Noonan syndrome. Pediatr Blood Cancer 62: 1084-1086, 2015.

27. Hu Z, Wang X, Fang H, Liu Y, Chen D, Zhang Q, Liu X, Wei D, Qu C and Wang S: A tyrosine phosphatase SHP2 gain-of-function mutation enhances malignancy of breast carcinoma. Oncotarget 7: 5664-5676, 2016.

28. Beigbeder A, Chartier FJM and Bisson N: MPZL1 forms a signalling complex with GRB2 adaptor and PTPN11 phosphatase in HER2-positive breast cancer cells. Sci Rep 7: 11514, 2017

29. Zhang Q, Li Y, Zhao R, Wang X, Fan C, Xu Y, Liu Y, Li J and Wang S: The gain-of-function mutation E76K in SHP2 promotes CAC tumorigenesis and induces EMT via the Wnt/ $\beta$-catenin signaling pathway. Mol Carcinog 57: 619-628, 2018.

30. Gagné-Sansfaçon J, Coulombe G, Langlois MJ, Langlois A, Paquet M, Carrier J, Feng GS, Qu CK and Rivard N: SHP-2 phosphatase contributes to KRAS-driven intestinal oncogenesis but prevents colitis-associated cancer development. Oncotarget 7 : 65676-65695, 2016.

31. Zhang N, Liu H, Yue G, Zhang Y, You J and Wang H: Molecular Heterogeneity of Ewing Sarcoma as Detected by Ion Torrent Sequencing. PLoS One 11: e0153546, 2016.

32. Je EM, Choi YJ, Yoo NJ and Lee SH: Oncogenic PTPN11 mutations are rare in solid tumors. Pathol Oncol Res 21: 225-227, 2015

33. Martinelli S, Carta C, Flex E, Binni F, Cordisco EL, Moretti S Puxeddu E, Tonacchera M, Pinchera A, McDowell HP, et al: Activating PTPN11 mutations play a minor role in pediatric and adult solid tumors. Cancer Genet Cytogenet 166: 124-129, 2006.

34. Zhuo C, Shao M, Chen C, Lin C, Jiang D, Chen G, Tian H, Wang L, Li J and Lin X: Chemotherapy effectiveness and prognosis of gastric cancer influenced by PTPN11 polymorphisms. Cell Physiol Biochem 39: 1537-1552, 2016.

35. He C, Tu H, Sun L, Xu Q, Li P, Gong Y, Dong N and Yuan Y: Helicobacter pylori-related host gene polymorphisms associated with susceptibility of gastric carcinogenesis: A two-stage case-control study in Chinese. Carcinogenesis 34: 1450-1457, 2013

36. Zhu F, Loh M, Hill J, Lee S, Koh KX, Lai KW, Salto-Tellez M, Iacopetta B, Yeoh KG and Soong R; Singapore Gastric Cancer Consortium: Genetic factors associated with intestinal metaplasia in a high risk Singapore-Chinese population: A cohort study. BMC Gastroenterol 9: 76, 2009.

37. Jiang J, Jia ZF, Kong F, Jin MS, Wang YP, Tian S, Suo J and Cao X: Association of polymorphism of PTPN 11 encoding SHP-2 with gastric atrophy but not gastric cancer in Helicobacter pylori seropositive Chinese population. BMC Gastroenterol 12: 89, 2012

38. Hishida A, Matsuo K, Goto Y, Naito M, Wakai K, Tajima K and Hamajima N: Associations of a PTPN11 G/A polymorphism at intron 3 with Helicobactor pylori seropositivity, gastric atrophy and gastric cancer in Japanese. BMC Gastroenterol 9: 51, 2009.

39. Sapari NS, Loh M, Vaithilingam A and Soong R: Clinical potential of DNA methylation in gastric cancer: A meta-analysis. PLoS One 7: e36275, 2012.

40. Li J, Chen C, Bi X, Zhou C, Huang T, Ni C, Yang P, Chen S, Ye M and Duan S: DNA methylation of CMTM3, SSTR2, and MDFI genes in colorectal cancer. Gene 630: 1-7, 2017.
41. Kristensen LS, Mikeska T, Krypuy M and Dobrovic A: Sensitive Melting Analysis after Real Time-Methylation Specific PCR (SMART-MSP): High-throughput and probe-free quantitative DNA methylation detection. Nucleic Acids Res 36: e42, 2008.

42. Testino G, Testino R and Ancarani AO: Helicobacter pylori and gastric carcinogenesis. Recenti Prog Med 92: 573-577, 2001 (In Italian).

43. Jiang J, Jin MS, Kong F, Wang YP, Jia ZF, Cao DH, Ma HX, Suo $\mathrm{J}$ and Cao XY: Increased expression of tyrosine phosphatase SHP-2 in Helicobacter pylori-infected gastric cancer. World J Gastroenterol 19: 575-580, 2013.

44. Fukushige S and Horii A: DNA methylation in cancer: A gene silencing mechanism and the clinical potential of its biomarkers. Tohoku J Exp Med 229: 173-185, 2013.

45. Li S, Hsu DD, Wang H and Feng GS: Dual faces of SH2-containing protein-tyrosine phosphatase Shp2/PTPN11 in tumorigenesis. Front Med 6: 275-279, 2012.

46. Bard-Chapeau EA, Li S, Ding J, Zhang SS, Zhu HH, Princen F, Fang DD, Han T, Bailly-Maitre B, Poli V, et al: Ptpn11/Shp2 acts as a tumor suppressor in hepatocellular carcinogenesis. Cancer Cell 19: 629-639, 2011.

47. Jiang C, Hu F, Tai Y, Du J, Mao B, Yuan Z, Wang Y and Wei L: The tumor suppressor role of Src homology phosphotyrosine phosphatase 2 in hepatocellular carcinoma. J Cancer Res Clin Oncol 138: 637-646, 2012.

48. Xu R, Yu Y, Zheng S, Zhao X, Dong Q, He Z, Liang Y, Lu Q, Fang Y, Gan X, et al: Overexpression of Shp2 tyrosine phosphatase is implicated in leukemogenesis in adult human leukemia. Blood 106: 3142-3149, 2005.

49. Lucci MA, Orlandi R, Triulzi T, Tagliabue E, Balsari A and Villa-Moruzzi E: Expression profile of tyrosine phosphatases in HER2 breast cancer cells and tumors. Cell Oncol 32: 361-372, 2010.

50. Hu ZQ, Ma R, Zhang CM, Li J, Li L, Hu ZT, Gao QI and Li WM: Expression and clinical significance of tyrosine phosphatase SHP2 in thyroid carcinoma. Oncol Lett 10: 1507-1512, 2015.

51. Cai P, Guo W, Yuan H, Li Q, Wang W, Sun Y, Li X and Gu Y: Expression and clinical significance of tyrosine phosphatase SHP-2 in colon cancer. Biomed Pharmacother 68: 285-290, 2014.

52. Luo X, Liao R, Hanley KL, Zhu HH, Malo KN, Hernandez C, Wei X, Varki NM, Alderson N, Chu C, et al: Dual Shp2 and Pten deficiencies promote non-alcoholic steatohepatitis and genesis of liver tumor-initiating cells. Cell Rep 17: 2979-2993, 2016.

53. Dong S, Li FQ, Zhang Q, Lv KZ, Yang HL, Gao Y and Yu JR: Expression and clinical significance of SHP2 in gastric cancer. J Int Med Res 40: 2083-2089, 2012.

54. Kim JS, Shin OR, Kim HK, Cho YS, An CH, Lim KW and Kim SS Overexpression of protein phosphatase non-receptor type 11 (PTPN11) in gastric carcinomas. Dig Dis Sci 55: 1565-1569, 2010.

55. Tramacere I, Negri E, Pelucchi C, Bagnardi V, Rota M, Scotti L Islami F, Corrao G, La Vecchia C and Boffetta P: A meta-analysis on alcohol drinking and gastric cancer risk. Ann Oncol 23: 28-36, 2012.

56. Wang D, Li C, Xu Y, Xing Y, Qu L, Guo Y, Zhang Y, Sun X and Suo J: Clinicopathological characteristics and prognosis of alpha-fetoprotein positive gastric cancer in Chinese patients. Int J Clin Exp Pathol 8: 6345-6355, 2015.

57. Han T, Xiang DM, Sun W, Liu N, Sun HL, Wen W, Shen WF, Wang RY, Chen C, Wang X, et al: PTPN11/Shp2 overexpression enhances liver cancer progression and predicts poor prognosis of patients. J Hepatol 63: 651-660, 2015.

58. Chang W, Gao X, Han Y, Du Y, Liu Q, Wang L, Tan X, Zhang Q, Liu Y, Zhu Y, et al: Gene expression profiling-derived immunohistochemistry signature with high prognostic value in colorectal carcinoma. Gut 63: 1457-1467, 2014

59. Chen SJ, Liu H, Liao CT, Huang PJ, Huang Y, Hsu A, Tang P, Chang YS, Chen HC and Yen TC: Ultra-deep targeted sequencing of advanced oral squamous cell carcinoma identifies a mutation-based prognostic gene signature. Oncotarget 6: 18066-18080, 2015.

his work is licensed under a Creative Commons Attribution-NonCommercial-NoDerivatives 4.0 International (CC BY-NC-ND 4.0) License. 